\title{
Precise Isotopic Analysis of Mo in Seawater Using Multiple Collector-Inductively Coupled Mass Spectrometry Coupled with a Chelating Resin Column Preconcentration Method
}

\author{
Yusuke Nakagawa, * M. Lutfi Firdaus, Kazuhiro Norisuye, Yoshiki Sohrin, Keita Irisawa, ${ }^{\dagger}$ and \\ Takafumi Hiratał \\ Institute for Chemical Research, Kyoto University, Uji, Kyoto 611-0011, Japan, Japan Atomic Energy Agency, \\ Shirakatashirane 2-4, Tokai, Ibaraki 319-1195, Japan, and Laboratory for Planetary Sciences, Tokyo Institute of \\ Technology, O-okayama 2-12-1, Meguro, Tokyo 152-8551, Japan
}

It is widely recognized that the natural isotopic variation of Mo can provide crucial information about the geochemical circulation of Mo, and the ocean is an important reservoir of Mo. To obtain precise isotopic data on Mo in seawater samples using multiple collector-inductively coupled plasma mass spectrometry (MC-ICPMS), we have developed a preconcentration technique using 8-hydroxyquinoline bonded covalently to a vinyl polymer resin (TSK-8HQ). By optimizing the procedure, Mo in seawater could be effectively separated from matrix elements such as alkali, alkaline earth, and transition metals. With this technique, even with a 50-fold enrichment factor, the changes in the ${ }^{98} \mathrm{Mo} /{ }^{95} \mathrm{Mo}$ ratio during preconcentration were smaller than twice the standard deviation (SD) in this study. Mass discrimination of Mo isotopes during the measurement was externally corrected for by normalizing ${ }^{86} \mathrm{Sr} /{ }^{88} \mathrm{Sr}$ to 0.1194 using an exponential law. We evaluated $\delta^{98 / 95}$ Mo to a precision of $\pm 0.08 \%$ ( $\left.\pm 2 \mathrm{SD}\right)$; this value was found to be less than one-third of previous reported values. Moreover, we were able to determine an accurate ratio for every pair of stable Mo isotopes, which was impossible with previous methods owing to the isobaric interference from the external elements $(\mathrm{Zr}$ and $\mathrm{Ru})$. In this study, $\delta^{92 / 98}$ Mo in seawater was first determined so that it had the smallest relative error. We applied the proposed method to four kinds of seawater samples. The Mo compositions were constant among them, with average $\delta^{98 / 95}$ Mo and $\delta^{92 / 98}$ Mo values of $2.45 \pm 0.11$ and $-4.94 \pm 0.09 \%$ ( $\pm 2 \mathrm{SD})$, respectively. Our data indicate that seawater is enriched in heavy Mo isotopes than previously reported.

The recently developed multiple collector-inductively coupled plasma mass spectrometry (MC-ICPMS) technique has revealed that natural isotopic variations of heavy elements (e.g., $\mathrm{Cu}, \mathrm{Zn}$,

* To whom correspondence should be addressed. E-mail: ynakagawa@ inter3.kuicr.kyoto-u.ac.jp. Tel: +81 77438 3097. Fax: +81 774383099.

$\dagger$ Japan Atomic Energy Agency.

* Laboratory for Planetary Sciences.
$\mathrm{Fe}$, and $\mathrm{Cd}$ ) are common in nature. ${ }^{1-7}$ These nontraditional studies on stable isotopes have revolutionized the environmental, geological, and cosmological sciences.

Among the heavy elements, Mo is of particular importance. Molybdenum has seven naturally occurring isotopes, which show a percent mass spread of $\sim 10 \%$. Series of isotopic studies have revealed that Mo isotopic compositions are strongly related to redox conditions. ${ }^{8-14}$ Isotopic variations of Mo in seawater, oxic sediments ( $\mathrm{Fe}-\mathrm{Mn}$ crusts and pelagic clays), and euxinic sediments have been determined to be $\delta^{98 / 95} \mathrm{Mo}=2.3,-0.8$ to -0.3 , and 1.7 to $2.3 \%$, respectively, using $\delta$ notation, relative to the Johnson Matthey Mo plasma standard. ${ }^{10,11}$ The level of isotopic fractionation during Mo removal from seawater to oxic sediments is large $\left(\Delta \delta^{98 / 95} \mathrm{Mo}=-2.7\right.$ to $\left.-3.1 \%\right)$ because the fraction of Mo removed is very small. In contrast, since most of Mo in seawater are removed under euxinic conditions, the resulting level of isotopic fractionation is small $\left(\Delta \delta^{98 / 95} \mathrm{Mo}=-0.6\right.$ to $\left.0.0 \%\right)$. Thus, due to this large variation in the level of isotopic fractionation, stable Mo isotopes in sediments can provide crucial

(1) Asael, D.; Matthews, A.; Bar-Matthews, M.; Halicz, L. Chem. Geol. 2007, 243, 238-254.

(2) Maréchal, C. N.; Télouk, P.; Albarède, F. Chem. Geol. 1999, 156, 251273.

(3) Bermin, J.; Vance, D.; Archer, C.; Statham, P. J. Chem. Geol. 2006, 226, 280-297.

(4) Maréchal, C.; Albarède, F. Geochim. Cosmochim. Acta 2002, 66, 14991509.

(5) Arnold, G. L.; Weyer, S.; Anbar, A. D. Anal. Chem. 2004, 76, 322-327.

(6) Borrok, D. M.; Wanty, R. B.; Ridley, W. I.; Wolf, R.; Lamothe, P. J.; Adams, M. Chem. Geol. 2007, 242, 400-414.

(7) Ripperger, S.; Rehkamper, M. Geochim. Cosmochim. Acta 2007, 71, 631642.

(8) Barling, J.; Arnold, G. L.; Anbar, A. D. Earth Planet. Sci. Lett. 2001, 193, 447-457.

(9) Mcmanus, J.; Nägler, T. F.; Siebert, C.; Wheat, C. G.; Hammond, D. E. Geochem. Geophys. Geosyst. 2002, 3, 1078.

(10) Siebert, C.; Nägler, T. F.; Von Blanckenburg, F.; Kramers, J. D. Earth Planet. Sci. Lett. 2003, 211, 159-171.

(11) Arnold, G. L.; Anbar, A. D.; Barling, J.; Lyons, T. W. Science 2004, 304, 87-90.

(12) Siebert, C.; Mcmanus, J.; Bice, A.; Poulson, R.; Berelson, W. M. Earth Planet. Sci. Lett. 2006, 241, 723-733.

(13) Reitz, A.; Wille, M.; Nägler, T. F.; Lange, G. J. D. Chem. Geol. 2007, 245, 1-8.

(14) Poulson, R. L.; Siebert, C.; Mcmanus, J.; Berelson, W. M. Geology 2006, $34,617-620$.

Analytical Chemistry, Vol. 80, No. 23, December 1, 2008

9213 
information in decoding the redox conditions in the paleocean. ${ }^{10,11,15}$ The Mo isotopic ratios of natural geochemical samples can also be used to elucidate the global circulation and mass balance of Mo both in the present and in the past, which is not resolved by the concentrations alone. Moreover, Mo is essential in biological processes as the active sites in enzymes such as nitrogenase and nitrate reductase. ${ }^{16-18}$ Since biological activity probably causes the isotopic fractionation, it is reasonable to expect that Mo isotopic data for organisms could be the key to evaluating the elemental absorption or metabolism efficiency.

At present, Mo isotopic data for only six seawater samples have been reported, and the resulting $\delta^{98 / 95}$ Mo value exhibits a large variation ranging from 2.22 to $2.46 \%{ }^{8,10}$ Despite the significant level of isotopic variation $(\sim 0.24 \%)$, it was concluded that the Mo isotopic composition of seawater is uniform in the oceans. In these studies, Mo in seawater was preconcentrated using an anionexchange column ${ }^{10}$ or a chelating resin Chelex-100 column. ${ }^{8}$ In another study, although high recovery was achieved, it was also found that Mo was isotopically fractionated during the ionexchange separation procedures. ${ }^{19}$ Furthermore, it has been reported that alkali, alkaline earth, and other transition metals, which are matrix elements in seawater, cannot be adequately removed using the Chelex-100. ${ }^{20,21}$ These previous studies used $\mathrm{Zr}$ or $\mathrm{Ru}$ as the external element, which include isobaric isotopes of Mo $\left({ }^{92} \mathrm{Zr},{ }^{94} \mathrm{Zr},{ }^{96} \mathrm{Zr},{ }^{96} \mathrm{Ru},{ }^{98} \mathrm{Ru},{ }^{100} \mathrm{Ru}\right)$. Thus, it was not possible to determine some Mo isotopes.

To obtain highly precise Mo isotopic data for seawater, it is necessary to develop a new preconcentration and isotopic analytical technique. We applied a new preconcentration method for Mo that uses 8-hydroxyquinoline bonded covalently to a vinyl polymer resin (TSK-8HQ), which shows excellent separation of Mo and matrix elements. Moreover, we employed a new Sr-external correction for the isotopic ratio measurements. This technique can provide information on all Mo isotopes and allow us to obtain highly precise isotopic data in seawater by means of the large relative mass differences between the isotopes of Mo. In this paper, we describe the new technique and present reliable isotopic data on Mo in both seawater reference materials for trace metals and coastal seawater samples. These data are expected to be benchmarks for the geochemistry of stable Mo isotopes.

\section{EXPERIMENTAL SECTION}

Reagents and Materials. Ultrahigh-purity tetramethylammonium hydroxide (TMAH; Tamapure-AA, Tama Chemicals) and $\mathrm{NH}_{3}, \mathrm{HNO}_{3}, \mathrm{HCl}$, and $\mathrm{HF}$ (poisonous metal analysis grade, WAKO Pure Chemical Industries) were used for the seawater analysis, preliminary experiments, and cleaning of materials. Metal standard solutions (WAKO) were used for the concentration measurements. The Johnson Matthey Specpure Mo plasma standard solution

(15) Anbar, A. D.; Knoll, A. H. Science 2002, 297, 1137-1142.

(16) Raven, J. A. New Phytol. 1988, 109, 279-287.

(17) Williams, R. J. P.; Frausto Da Silva, J. J. R. Biochem. Biophys. Res. Commun. 2002, 292, 293-299.

(18) Barney, B. M.; Lee, H.-I.; Santos, P. C. D.; Hoffman, B. M.; Dean, D. R.; Seefeldt, L. C. Dalton Trans. 2006, 2277-2284.

(19) Anbar, A. D.; Knab, K. A.; Barling, J. Anal. Chem. 2001, 73, 1425-1431.

(20) Yabutani, T.; Ji, S.; Mouri, F.; Sawatari, H.; Itoh, A.; Chiba, K.; Haraguchi, H. Bull. Chem. Soc. Jpn. 1999, 72, 2253-2260.

(21) Zhu, Y.; Itoh, A.; Fujimori, E.; Umemura, T.; Haraguchi, H. Bull. Chem. Soc. Jpn. 2005, 78, 659-667.
1. $\mathrm{pH}$ conditioning 2. Mo collection 3. Sea salt washing

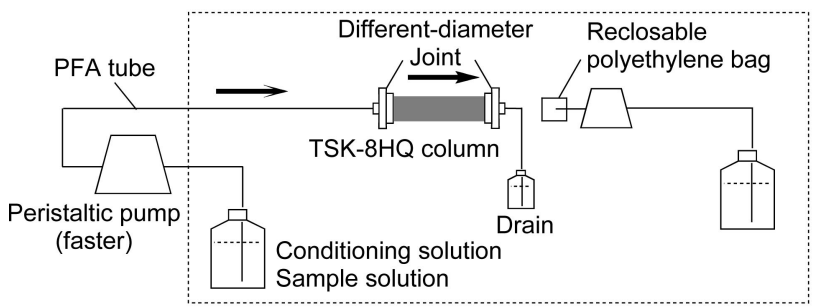

\section{Mo elution 5. Cleaning}

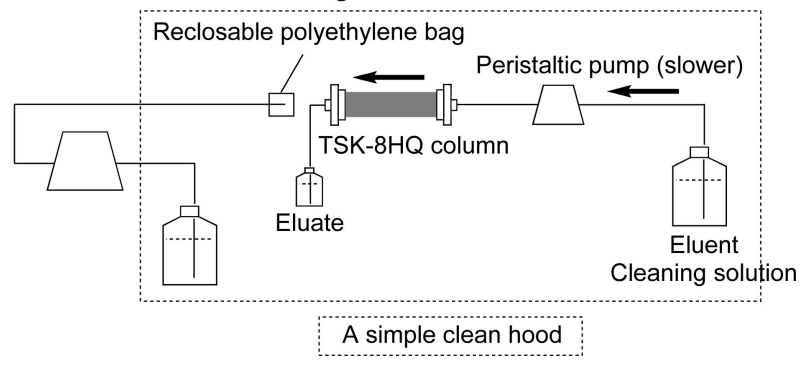

Figure 1. Schematic diagram of the present concentration system for Mo.

(Stock No. 38719, Lot No. 012773) and NIST SRM 987 (Sr) were used as the isotopic standards of Mo and Sr, respectively. Working standards were prepared by dilution on a weight basis. Ultrapure water prepared with a Milli-Q Gradient-A10 system (Millipore) was used to prepare all solutions and is referred to as Milli- $Q$ water hereafter. All solutions and seawater samples were stored in lowdensity polyethylene (LDPE) bottles (Nalge Nunc Int.), which, along with the other materials, were cleaned as described in Firdaus et al. ${ }^{22}$

Preparation of TSK-8HQ Resin Column and Preconcentration System. We used TSK- 8 HQ resin for the separation and enrichment of Mo. For the resin column, we adopted the synthetic approach developed by Dierssen et al.:23 8 -hydroxyquinoline was immobilized on a hydrophilic vinyl polymer resin through the single-step reaction of AF-Epoxy-650 M (40-90- $\mu \mathrm{m}$ bead size; Tosoh Corp.) with 5-amino-8-hydroxyquinoline (Tokyo Kasei Kogyo). TSK-8HQ resin ( $0.22 \mathrm{~g}$ of dry weight) was packed in a column as shown in Firdaus et al. ${ }^{22} \mathrm{~A}$ concentration system was constructed in a clean hood with the TSK-8HQ column, perfluoroalkoxy (PFA) tubes, joints of different diameters, and two peristaltic pumps (Figure 1). A TygonLFL tube (1.6-mm i.d., Saint-Gobain) was used for the faster pump (Masterflex 7520-40, Cole-Parmer) and a Tygon tube (1.15-mm i.d., Saint-Gobain) was used for the slower pump (SMP-23, EYELA). The $\mathrm{pH}$ conditioning and sample solutions were passed to the column with the faster pump and the eluent with the slower pump. Altogether, there were two systems in the clean hood that could treat two samples simultaneously.

Evaporation System. An evaporation system was constructed with PFA tubes, PFA jars, and LDPE bottles (Figure 2 ). The eluate was collected in a PFA jar and evaporated to dryness at $200{ }^{\circ} \mathrm{C}$ on a hot plate. For faster evaporation, clean air was continuously blown into the jar after passing through a $0.8-\mu \mathrm{m}$ polypropylene filter cartridge and traps of $1 \mathrm{M} \mathrm{HNO}_{3}$

(22) Firdaus, M. L.; Norisuye, K.; Sato, T.; Urushihara, S.; Nakagawa, Y.; Umetani, S.; Sohrin, Y. Anal. Chim. Acta 2007, 583, 296-302.

(23) Dierssen, H.; Balzer, W.; Landing, W. M. Mar. Chem. 2001, 73, 173-192. 
Tube connector (separate line)

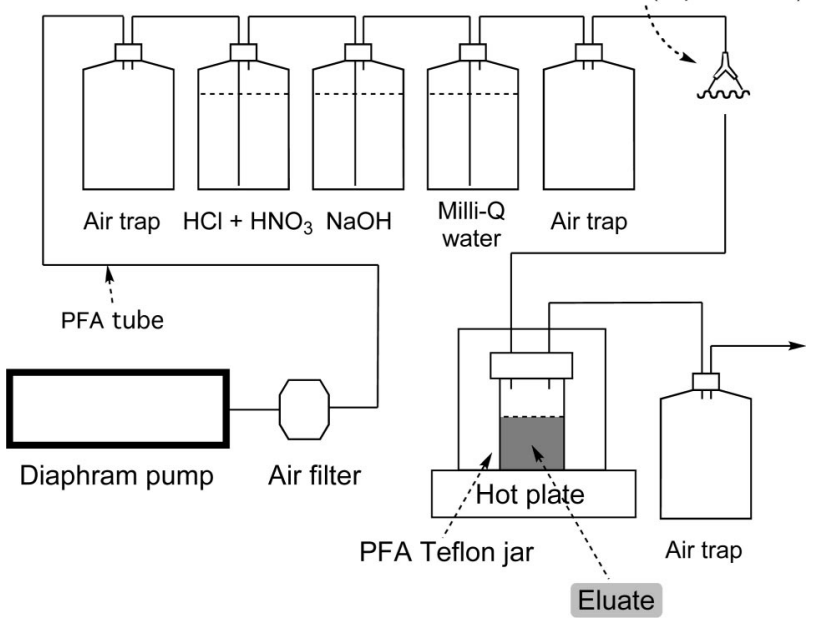

Figure 2. Schematic diagram of evaporation system.

Table 1. Details of the Instrument and the Operation Parameters of MC-ICPMS

(1) MC-ICPMS instrument

$\mathrm{Nu}$ Instruments Nu Plasma 500

(2) ICP ion source

ICP

power

argon gas flow rates

cooling

auxiliary

nebulizer

$27.12 \mathrm{MHz}$

$1.35 \mathrm{~kW}$ forward, $<5 \mathrm{~W}$ ref

$13 \mathrm{~L} \mathrm{~min}^{-1}$

$0.7 \mathrm{~L} \mathrm{~min}^{-1}$

$1.06 \mathrm{~L} \mathrm{~min}^{-1}$

(3) mass spectrometer

ion energy

extraction

analysis mode

ion detection

typical transmission

(4) data acquisition

blank mode

integration time

number of cycles

total analysis time

(5) normalization

mass bias correction

$4000 \mathrm{~V}$

$2250 \mathrm{~V}$

dynamic mode

analogue by Faraday

$15 \mathrm{~V}$ per $\mu \mathrm{g} \mathrm{g}^{-1}$

on-peak baseline

$5 \mathrm{~s}$

40 (20 cycles $\times 2$ blocks)

$\sim 10 \mathrm{~min}$

(6) sample injection

nebulizer

sample uptake rate

External correction using NIST $987 \mathrm{Sr}$

Glass Expansion MicroMist

150-180 $\mu \mathrm{L} \mathrm{min}^{-1}$ (not pumped)

$+1 \mathrm{M} \mathrm{HCl}, 4 \mathrm{M} \mathrm{NaOH}$, and Milli-Q water. The air was distributed into eightPFAjars to treat eight samples simultaneously.

Samples. Coastal seawater was collected in 6-L polyethylene bottles at the Suruga Bay Deep Seawater Intake and Supply Facility, Japan. This seawater was sampled from $10 \mathrm{~km}$ offshore at a depth of $687 \mathrm{~m}$ in Suruga Bay. Within a few days after sampling, the seawater was filtered through a $0.22-\mu \mathrm{m}$ membrane filter unit (Sterivex SVGP01050, Millipore) and treated with $\mathrm{HCl}$ to adjust the $\mathrm{pH}$ to 2.0. This solution was used for the preliminary experiments. We analyzed a certified seawater reference material for trace metals (NASS-5, National Research Council of Canada) that was collected at a depth of $10 \mathrm{~m}, 35 \mathrm{~km}$ southeast of Halifax, NS, Canada, and SAFe reference materials of surface water (S1, bottle No. 123) and deep water from a depth of $1000 \mathrm{~m}$ (D2, bottle No. 275) collected at $30^{\circ} \mathrm{N}, 140^{\circ} \mathrm{W}$ in the eastern North Pacific during the SAFe program. ${ }^{24}$ These three reference materials were

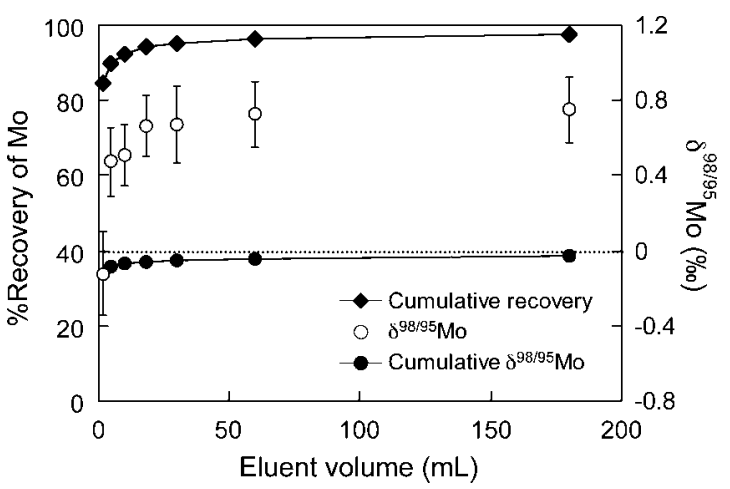

Figure 3. Cumulative recovery of Mo from the separation procedure using a TSK-8HQ chelating resin column (filled diamonds). The $\delta^{98 / 95} \mathrm{Mo}$ for each fraction (open circles) and the cumulative $\delta^{98 / 95} \mathrm{Mo}$ (filled circles) are also shown.

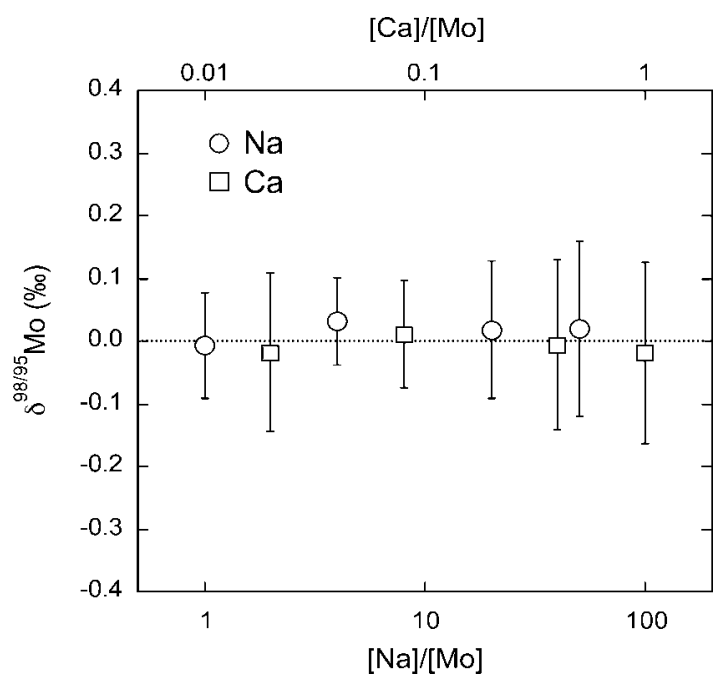

Figure 4. Effect of $\mathrm{Na}$ and $\mathrm{Ca}$ on measured $\delta^{98 / 95} \mathrm{Mo}$. Mass discrimination was corrected by the external correction using $\mathrm{Sr}$ standard solution. Error bars indicate \pm 2 SD uncertainties.

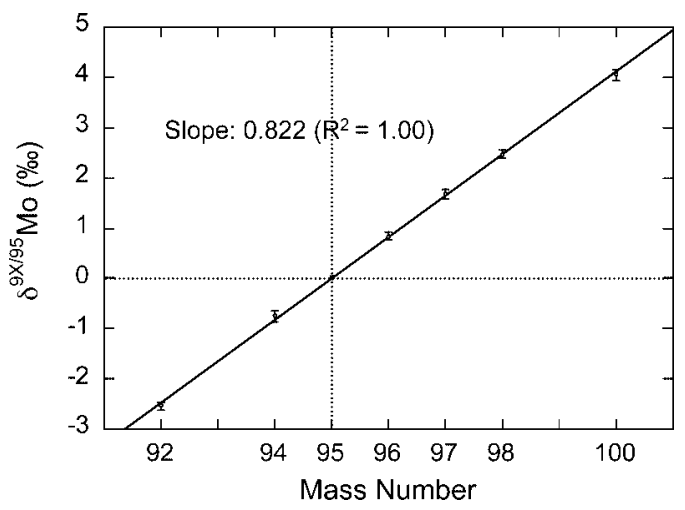

Figure 5. Measured $\delta^{9 \times / 95}$ Mo for the Suruga Bay deep seawater samples. Error bars are \pm 2 SD uncertainties calculated based on 13 replicate analyses.

chosen because they are easily available and can therefore be applied for interlaboratory comparison.

Procedure for Preconcentration. Prior to use, the TSK- $8 \mathrm{HQ}$ column was mounted on the concentration system and washed by passing $20 \mathrm{~mL}$ of $3 \mathrm{M} \mathrm{HNO}_{3}\left(1 \mathrm{~mL} \mathrm{~min}^{-1}\right), 20 \mathrm{~mL}$ of $2 \mathrm{M} \mathrm{NH}_{3}$ $\left(1 \mathrm{~mL} \mathrm{~min}^{-1}\right)$, and $100 \mathrm{~mL}$ of Milli-Q water $\left(2.5 \mathrm{~mL} \mathrm{~min}^{-1}\right)$. Fifty milliliters of $0.01 \mathrm{M} \mathrm{HCl}$ was passed through the column to 
Table 2. Employment of Faraday Collector Array for Measurement of Mo Isotopic Ratios

\begin{tabular}{|c|c|c|c|c|c|c|c|c|c|c|c|c|}
\hline & \multicolumn{12}{|c|}{ cup configuration } \\
\hline & L5 & $\mathrm{L} 4$ & L3 & L2 & L1 & $A x$ & H1 & $\mathrm{H} 2$ & H3 & $\mathrm{H} 4$ & H5 & $\mathrm{H} 6$ \\
\hline $\begin{array}{l}\text { Mo } \\
\text { mass } \\
\text { abundances }\end{array}$ & $\begin{array}{l}92 \\
14.8\end{array}$ & 93 & $\begin{array}{l}94 \\
17.4\end{array}$ & $\begin{array}{l}95 \\
15.9\end{array}$ & 95.5 & $\begin{array}{l}96 \\
16.7\end{array}$ & 96.5 & $\begin{array}{l}97 \\
9.55\end{array}$ & 97.5 & $\begin{array}{l}98 \\
24.1\end{array}$ & 99 & $\begin{array}{l}100 \\
9.63\end{array}$ \\
\hline $\begin{array}{l}\mathrm{Sr} \\
\text { mass } \\
\text { abundances }\end{array}$ & 82 & 83 & $\begin{array}{l}84 \\
0.557\end{array}$ & 85 & 85.5 & $\begin{array}{l}86 \\
9.87\end{array}$ & 86.5 & $\begin{array}{l}87 \\
7.00\end{array}$ & 87.5 & $\begin{array}{l}88 \\
82.6\end{array}$ & 89 & 90 \\
\hline
\end{tabular}

\section{Table 3. Mo Isotope Ratios and Concentration in NASS-5, SAFe S1, and D2, and Suruga Bay Deep Seawater}

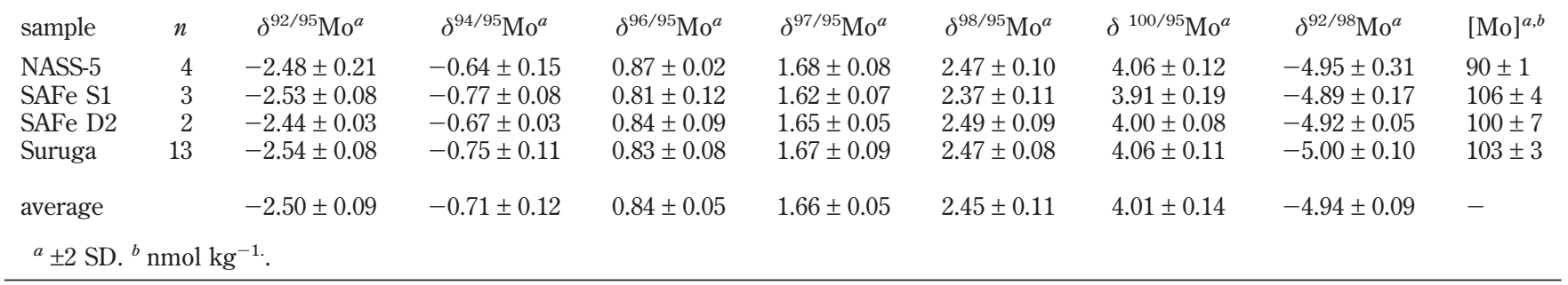

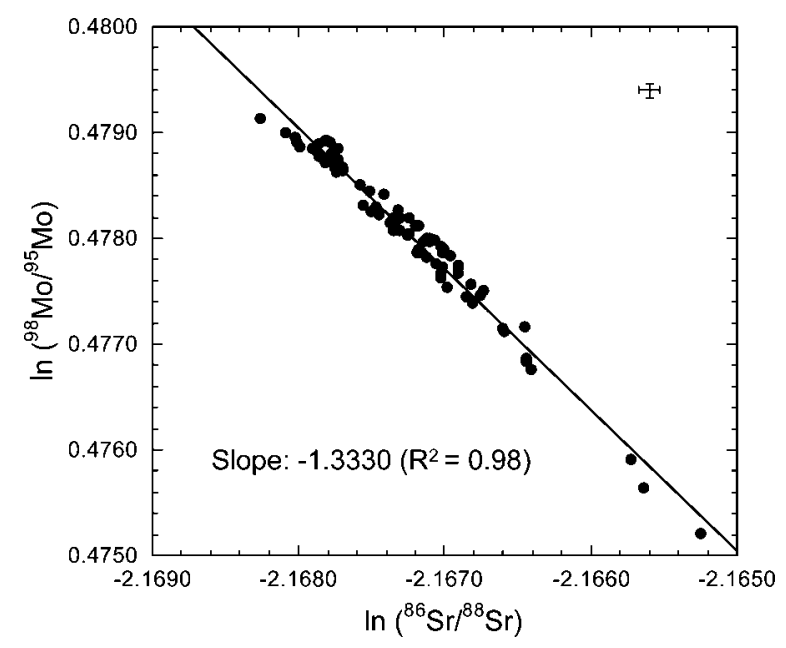

Figure 6. Logarithmic plots of ${ }^{98} \mathrm{Mo} /{ }^{95} \mathrm{Mo}$ against ${ }^{86} \mathrm{Sr} /{ }^{88} \mathrm{Sr}$. Data were obtained for an analyte solution prepared using the Johnson Matthey Mo standard. Typical \pm 2 SD error bars are given on the upper right.

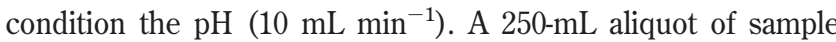
solution was adjusted with $\mathrm{HCl}$ to $\mathrm{pH} 2.0$ and then passed through the column, followed by $250 \mathrm{~mL}$ of $0.01 \mathrm{M} \mathrm{HCl}$ to remove the sea salts remaining in the column $\left(10 \mathrm{~mL} \mathrm{~min}^{-1}\right.$ each). The adsorbed Mo was eluted by passing $60 \mathrm{~mL}$ of $2 \mathrm{M} \mathrm{NH}_{3}$ in the direction opposite to that of sample loading $\left(0.5 \mathrm{~mL} \mathrm{~min}{ }^{-1}\right)$. The eluate was evaporated to dryness using the closed evaporation system, and the residue was redissolved in $5 \mathrm{~mL}$ of $0.05 \% \mathrm{TMAH}$. This solution was ready for Mo isotopic ratio measurements.

Instrumentation. An Optima 2000 DV ICP-atomic emission spectrometry (ICP-AES; Perkin-Elmer) was used to measure

(24) Johnson, K. S.; Boyle, E.; Bruland, K.; Coale, K.; Measures, C.; Moffett, J.; Aguilar-Islas, A.; Barbeau, K.; Bergquist, B.; Bowie, A.; Buck, K.; Cai, Y.; Chase, Z.; Cullen, J.; Doi, T.; Elrod, V.; Fitzwater, S.; Gordon, M.; King, A.; Laan, P.; Laglera-Baquer, L.; Landing, W.; Lohan, M.; Mendez, J.; Milne, A.; Obata, H.; Ossiander, L.; Plant, J.; Sarthou, G.; Sedwick, P.; Smith, G. J.; Sohst, B.; Tanner, S.; Berg, S. V. D.; Wu, J. EOS Trans. AGU 2007, 88, 131. metals at the micromole per kilogram level in the preliminary experiments. An Elan DRC II quadrupole ICPMS (Q-ICPMS; Perkin-Elmer) was used for the rest of the measurements at lower concentrations $\left(\mathrm{pmol} \mathrm{\textrm {kg } ^ { - 1 }}\right.$ ). Details of the instruments and operating parameters are described in Firdaus et al. ${ }^{22,25}$ Mo isotopic ratios were determined using a $\mathrm{Nu}$ Plasma $500 \mathrm{MC}$ ICPMS (Nu Instruments). Details of this instrument and the operating parameters are summarized in Table 1 . The collectors employed for MC-ICPMS are shown in Table 2.

Molybdenum Isotopic Ratio Measurements. Correction of the mass discrimination effect is highly desired for accurate isotopic analysis, since the mass bias factors for the mass discrimination effect found in ICPMS are typically larger than those observed in the thermal ionization mass spectrometry. The mass discrimination effect observed in ICPMS is mainly caused by the space-charge effect within the plasma ion source and vacuum interface regions. ${ }^{26}$ It is now widely accepted that the exponential function results in the best correction. ${ }^{2,27}$ The exponential law function was based on the empirical assumption that the mass discrimination effect was mainly caused by the preferential transmission of ions in a mass spectrometer due to kinetic or diffusion processes. ${ }^{28}$ However, further precise isotopic data obtained by the MC-ICPMS technique have revealed that there still remained a systematical deviation in the resulting isotopic ratio data from the literature values. To overcome this, modified exponential law or $\beta$-law was widely adopted for the correction of the mass discrimination effect. ${ }^{2,27,29}$ The exponential law for Mo and Sr is defined as

(25) Firdaus, M. L.; Norisuye, K.; Nakagawa, Y.; Nakatsuka, S.; Sohrin, Y. J. Oceanogr. 2008, 64, 247-257.

(26) Hirata, T. Analyst 1996, 121, 1407-1411.

(27) Iizuka, T.; Hirata, T. Chem. Geol. 2005, 220, 121-137.

(28) Russell, W. A.; Papanastassiou, D. A.; Tombrello, T. A. Geochim. Cosmochim. Acta 1978, 42, 1075-1090.

(29) Irisawa, K.; Hirata, T. J. Anal. At. Spectrom. 2006, 21, 1387-1395. 


$$
\left.\left({ }^{9 X} \mathrm{Mo} /{ }^{9 Y} \mathrm{Mo}\right)_{\text {meas }}{ }^{9 X} \mathrm{Mo} /{ }^{9 Y} \mathrm{Mo}\right)_{\text {true }}=\left(M_{9 X} / M_{9 Y}\right)^{\beta_{\mathrm{Mo}}}
$$

and

$$
\left({ }^{86} \mathrm{Sr}{ }^{88} \mathrm{Sr}\right)_{\text {meas }} /\left({ }^{86} \mathrm{Sr}{ }^{88} \mathrm{Sr}\right)_{\text {true }}=\left(M_{86} / M_{88}\right)^{\beta_{\mathrm{Sr}}}
$$

where "meas" and "true" represent the measured and true isotopic ratios, respectively, and $M_{N}$ is the atomic mass of Mo and $\mathrm{Sr}$ isotopes. The values $\beta_{\mathrm{Mo}}$ and $\beta_{\mathrm{Sr}}$ are the magnitudes of mass bias per amu mass difference for Mo and Sr, respectively.

These equations result in the following equation:

$$
\begin{aligned}
& \left({ }^{9 \mathrm{Xo}} /{ }^{9 \mathrm{Y}} \mathrm{Mo}\right)_{\text {corr }}= \\
& \left({ }^{9 X} \mathrm{Mo} /{ }^{9 \mathrm{Y}} \mathrm{Mo}\right)_{\text {meas }}\left[\left({ }^{86} \mathrm{Sr} /{ }^{88} \mathrm{Sr}\right)_{\text {ref }} /\left({ }^{86} \mathrm{Sr} /{ }^{88} \mathrm{Sr}\right)_{\text {meas }}\right]^{m} \\
& m=\left(\beta_{\mathrm{Mo}} / \beta_{\mathrm{Sr}}\right)\left[\ln \left(M_{9 \mathrm{X}} / M_{9 \mathrm{Y}}\right) / \ln \left(M_{86} / M_{88}\right)\right]
\end{aligned}
$$

where $\left({ }^{9 X} \mathrm{Mo} /{ }^{9 Y} \mathrm{Mo}\right)_{\text {corr }}$ is the corrected Mo isotopic ratios and $\left({ }^{86} \mathrm{Sr} /{ }^{88} \mathrm{Sr}\right)$ ref is the normalization value of $0.1194 .{ }^{30}$ In this study, we assumed that $\beta_{\mathrm{Mo}} / \beta_{\mathrm{Sr}}=1$. The sample solution was spiked with $\mathrm{Sr}$ to a concentration comparable with that of Mo. In this study, Mo and $\mathrm{Sr}$ were measured in the dynamic mode because they cannot be measured in the static mode with their $\sim 15 \%$ mass dispersion. The Mo and $\mathrm{Sr}$ isotopic signals were alternatively integrated for $5 \mathrm{~s}$ and repeated for 40 cycles ( 20 cycles $\times 2$ blocks).

To improve the accuracy of measurement, a sample-standard bracketing technique was also employed. The Mo isotopic ratios of all samples were normalized to those of the Johnson Matthey standard and expressed in $\delta$ notation to conform to a standard stable isotopic convention.

$$
\delta^{9 \mathrm{X} 9 \mathrm{Y}} \mathrm{Mo}(\%)=\left[\left({ }^{9 \mathrm{X}} \mathrm{Mo} /{ }^{9 \mathrm{Y}} \mathrm{Mo}\right)_{\mathrm{sample}} /\left({ }^{9 \mathrm{X}} \mathrm{Mo} /{ }^{9 \mathrm{Y}} \mathrm{Mo}\right)_{\mathrm{standard}}-\right.
$$

\section{RESULTS AND DISCUSSION}

TSK-8HQ Column. The exchange capacity of freshly synthesized TSK-8HQ for Mo was determined through batch extraction using a solution with $100 \mathrm{ppm} \mathrm{Mo}$ and $0.01 \mathrm{M} \mathrm{HCl}$; the capacity was found to be $0.83 \pm 0.01 \mathrm{mmol} \mathrm{g}^{-1}(n=2)$. After $\sim 30$ cycles of use in preconcentration experiments, the color of the resin changed from a dark reddish brown to a light reddish brown. The exchange capacity was $0.56 \pm 0.01 \mathrm{mmol} \mathrm{g}^{-1}(n=2)$ after 30 cycles. The decoloration was probably due to the cleavage of 5-amino-8-hydroxyquinoline from the vinyl polymer resin by the eluent and the washing solutions. Thus, we decided that when the color of the resin changed, the column would be replaced with a new one.

Optimization of Preconcentration Conditions. Initially, the effect of $\mathrm{pH}$ on the collection of Mo was examined. The $\mathrm{pH}$ of the sample solution and column was adjusted with $\mathrm{HCl}$ or $\mathrm{CH}_{3} \mathrm{COOH}-\mathrm{NH}_{3}$ buffer solution. A $20-\mathrm{mL}$ aliquot of filtered seawater was spiked with Mo to a final concentration of $1 \mathrm{ppm}$ and then passed through a TSK-8HQ column at a flow rate of 1 $\mathrm{mL} \mathrm{min}^{-1}$. The Mo concentration in the sample and drain was determined using the ICP-AES after 10-fold dilution. Molybdenum

(30) Nier, A. O. Phys. Rev. 1938, 54, 275-278. was quantitatively collected with the TSK-8HQ column from the sample solution at a pH between 1.0 and 5.0. In subsequent experiments, Mo collection was carried out at $\mathrm{pH} 2.0$ because it was expected that alkali, alkaline earth, and cationic transition metals would be hardly adsorbed on TSK-8HQ at pH 2.0.

The elution conditions for Mo were tested using the TSK- $8 \mathrm{HQ}$ column as follows: $20 \mathrm{~mL}$ of filtered seawater at $\mathrm{pH} 2.0$ containing $1 \mathrm{ppm}$ Mo was passed through the column, and the Mo adsorbed on the resin was eluted using $60 \mathrm{~mL}$ of the eluent at a flow rate of $1 \mathrm{~mL} \mathrm{~min}^{-1}$. The Mo concentration in the eluate was determined with the ICP-AES. With either $3 \mathrm{M} \mathrm{HNO}_{3}$ or $2 \mathrm{M} \mathrm{NH}_{3}$, more than $95 \%$ of the Mo adsorbed on the resin was eluted. In view of the separation of cationic transition metals, we used $2 \mathrm{M}$ $\mathrm{NH}_{3}$ as the eluent in subsequent experiments.

Recovery experiments were performed under the optimized collection and elution conditions discussed above. The samples used were 1-L aliquots of filtered seawater with or without Mo spike $\left(106 \mathrm{nmol} \mathrm{kg}^{-1}\right)$. The determined Mo concentrations in the spiked and unspiked seawater samples were $217 \pm 5$ and $111 \pm 2$ $n$ mol $\mathrm{kg}^{-1}(n=3)$, respectively. Thus, the resulting recovery of spiked Mo was $99 \pm 5 \%(n=3)$. This suggests that the naturally present Mo in seawater is also quantitatively collected.

When $250 \mathrm{~mL}$ of seawater was treated according to the optimized procedure, the eluate ( $60 \mathrm{~mL}$ of $2 \mathrm{M} \mathrm{NH}_{3}$ ) contained $\sim 40 \mathrm{ppb}$ Mo. However, precise isotopic ratio measurements using a Nu Plasma 500 required some $500 \mathrm{ppb}$ Mo. In addition, $2 \mathrm{M}$ $\mathrm{NH}_{3}$ made the Ar plasma unstable, resulting in deterioration of the data quality. Thus, the eluate was evaporated to dryness using the closed evaporation system, and the residue was then redissolved in $5 \mathrm{~mL}$ of $0.05 \%$ TMAH. We examined the recovery of Mo through the evaporation and redissolution using a seawater sample using the ICP-AES. We found that the Mo recovery was $100 \pm 1 \%(n=5)$.

The procedure blank was determined using $250 \mathrm{~mL}$ of Milli-Q water through preconcentration with an enrichment factor of 50 , as in the cases of the seawater samples; the blank was $3.2 \pm 0.2$ ng $(n=4)$. Since this is only $0.1 \%$ of the Mo content in a seawater $(\sim 2.5 \mu \mathrm{g})$, we concluded that the contamination from atmosphere, apparatuses and reagents is negligible.

Isotopic Fractionation During Preconcentration Procedure. It is widely recognized that the isotopic compositions of elements change through the ion chromatographic separation. ${ }^{29,31,32}$ We examined the isotopic fractionation during preconcentration using a TSK-8HQ column. A 200-mL aliquot containing $1 \mathrm{ppm}$ Mo and $0.01 \mathrm{M} \mathrm{HCl}$ was prepared from the Johnson Matthey Mo standard solution and passed through the TSK-8HQ column at a flow rate of $10 \mathrm{~mL} \mathrm{~min}^{-1}$. Then the adsorbed Mo was eluted with $2 \mathrm{M} \mathrm{NH}_{3}$ at a flow rate of $0.25 \mathrm{~mL} \mathrm{~min}^{-1}$. The eluate was separated into seven fractions $(0-2,2-5,5-10,10-18,18-30,30-60$, $60-180 \mathrm{~mL}$ ), evaporated to dryness and redissolved in $0.05 \%$ TMAH to afford seven solutions with Mo concentrations of $\sim 500$ ppb. The Mo recovery and isotopic ratios were determined for each fraction; the results are plotted in Figure 3. It was found that $85 \%$ of Mo was recovered in the first fraction, while the cumulative recovery reached $96 \%$ at $60 \mathrm{~mL}$ of eluent. $\delta^{98 / 95} \mathrm{Mo}$

(31) Roe, J. E.; Anbar, A. D.; Barling, J. Chem. Geol. 2003, 195, 69-85.

(32) Ohno, T.; Hirata, T. Anal. Sci. 2007, 23, 1275-1280. 
was $-0.12 \%$ for the first fraction and increased to $0.75 \%$ for the seventh fraction. Based on the cumulative $\delta^{98 / 95} \mathrm{Mo}$ (filled circles, Figure 3), we can estimate the minimum requirement of the eluent to avoid artifacts in the Mo isotopic ratio measurements. When the cumulative recovery of Mo was $96 \%$, the cumulative $\delta^{98 / 95} \mathrm{Mo}$ was $-0.04 \%$, which was less than \pm 2 SD for MC-ICPMS $( \pm 0.08 \%$ ). Therefore, the optimum eluent volume was determined to be 60 $\mathrm{mL}$. In this study, the magnitude of Mo isotopic fractionation through the preconcentration procedure was negligible because the isotopic fractionation during collection and elution was canceled out by the opposite flow of the eluent. The degree of the chemically induced isotopic fractionation obtained here is below one-fifth of that using an ion-exchange column. ${ }^{19,33}$

Matrix Effect. Coexisting elements in analyte solutions can interfere with Mo isotopic ratio measurements. Alkali and alkaline earth metals, which are the major elements in seawater, are easily ionized elements (EIE). When an analyte solution with a high concentration of EIE is analyzed by ICPMS, the space-charge effect is increased in the plasma and ion extraction stage, which could lead to isotopic ratios different from those without EIE. Sodium, $\mathrm{Mg}, \mathrm{Ca}$, and $\mathrm{K}$ exist in seawater at concentrations $10^{4}-10^{6}$ times that of Mo. The TSK-8HQ column preconcentration method effectively separated these elements from Mo, but the separation was not complete. In order to test the matrix effect of $\mathrm{Na}$ and $\mathrm{Ca}$, we measured the Mo isotopic ratios for standard solutions prepared from the Johnson Matthey Mo standard solution with various amounts of added $\mathrm{Na}$ and $\mathrm{Ca}$. Figure 4 illustrates the deviation from the $\delta^{98 / 95} \mathrm{Mo}$ value of the Mo solution without $\mathrm{Na}$ and $\mathrm{Ca}$. No significant change in measured $\delta^{98 / 95} \mathrm{Mo}$ was found even at ratios of $\mathrm{Na} / \mathrm{Mo}=50$ and $\mathrm{Ca} / \mathrm{Mo}=1$. The $\mathrm{Na} / \mathrm{Mo}$ and $\mathrm{Ca} / \mathrm{Mo}$ ratios in the analyte solutions of Suruga Bay deep seawater were $4.4 \pm 1.1$ and $0.08 \pm 0.02(n=3)$, respectively. Thus, we concluded that the matrix effects of alkali and alkaline earth metals were negligible.

Isobaric interference from elemental and molecular ions in the analyte solution may occur during the Mo isotopic ratio measurements. Zirconium interferes with ${ }^{92} \mathrm{Mo},{ }^{94} \mathrm{Mo}$, and ${ }^{96} \mathrm{Mo}$, and Ru interferes with ${ }^{96} \mathrm{Mo},{ }^{98} \mathrm{Mo}$, and ${ }^{100} \mathrm{Mo}$. The $\mathrm{Zr}$ concentration in the analyte solution of Suruga Bay deep seawater was $15 \pm 5 \mathrm{ppt}$ $(n=6)$; this was only $3 \times 10^{-6}$-fold the Mo concentration. Ruthenium was not detected in the analyte solution by Q-ICPMS. These results indicate that the effect of residual $\mathrm{Zr}$ and $\mathrm{Ru}$ on the measured Mo isotopic ratio is negligible. Polyatomic ions such as ${ }^{52} \mathrm{Cr}^{40} \mathrm{Ar}^{+},{ }^{55} \mathrm{Mn}^{40} \mathrm{Ar}^{+},{ }^{56} \mathrm{Fe}^{40} \mathrm{Ar}^{+},{ }^{60} \mathrm{Ni}^{40} \mathrm{Ar}^{+}$, and ${ }^{80} \mathrm{Se}^{16} \mathrm{O}^{+}$can also possibly interfere with the Mo isotopes. However, we found that the concentrations of $\mathrm{Cr}, \mathrm{Mn}, \mathrm{Fe}, \mathrm{Ni}$, and $\mathrm{Se}$ in the analyte solution were below $4 \mathrm{ppb}$ and their molecular ions had negligible influence on the Mo isotopic ratio measurements.

Figure 5 shows resulting $\delta^{9 \mathrm{X} / 95}$ Mo values for the Suruga Bay deep seawater samples. A good linear correlation indicates that the change in $\delta^{9 \mathrm{X} / 95} \mathrm{Mo}$ is controlled by a mass-dependent isotope effect and that the matrix effects are negligible. Therefore, the present technique, which combines a preconcentration method with Sr-external correction, affords accurate isotopic ratios for all pairs of stable Mo isotopes.

(33) Wieser, M. E.; Laeter, J. R. D.; Varner, M. D. Int. J. Mass Spectrom. 2007, $265,40-48$.

(34) Archer, C.; Vance, D. Geochim. Cosmochim. Acta 2007, 71, A33.
Accuracy and Precision. We measured the Mo isotopic ratios in Suruga Bay deep seawater samples. Here, we compare our $\delta^{98 /}$ ${ }_{95} \mathrm{Mo}$ and $\delta^{97 / 95} \mathrm{Mo}$ data with previously reported values. Our internal error at 40 cycles per measurement was typically \pm 0.09 and $\pm 0.08 \%$ ( $\pm 2 \mathrm{SD})$ for $\delta^{98 / 95} \mathrm{Mo}$ and $\delta^{97 / 95} \mathrm{Mo}$, respectively. The average $\delta^{98 / 95} \mathrm{Mo}$ and $\delta^{97 / 95}$ Mo for Suruga Bay deep seawater were $2.47 \pm 0.08$ and $1.67 \pm 0.09 \%$ ( $\pm 2 \mathrm{SD}, n=13$ ), respectively, where SD represents external error. The internal and external errors were at similar levels. Thus, $\delta^{9 \mathrm{X} / 9 \mathrm{Y}} \mathrm{Mo}$ can be determined to a precision of $\pm 0.03 \%$ / amu ( $\pm 2 \mathrm{SD}$ ). The range of our error is about one-third that of the previous data. ${ }^{8,10}$

We used $\mathrm{Sr}$ as the external element instead of $\mathrm{Zr}$ or Ru. Figure 6 shows logarithmic plots of ${ }^{98} \mathrm{Mo} /{ }^{95} \mathrm{Mo}$ against ${ }^{86} \mathrm{Sr} /{ }^{88} \mathrm{Sr}$. The linearity indicates that $\beta_{\mathrm{Mo}} / \beta_{\mathrm{Sr}}$ does not vary with time; the slope (" $m$ " in eqs 3 and 4) is -1.3330 . Compared to the value of $m$ assuming that $\beta_{\mathrm{Mo}} / \beta_{\mathrm{Sr}}=1$, the experimental value of $\beta_{\mathrm{Mo}} / \beta_{\mathrm{Sr}}$ was found to be 0.984 . Note that despite the fact that Mo and Sr have very different physical and chemical properties, this value is larger than ${ }_{\mathrm{Mo}} / \beta_{\mathrm{Zr}}(\sim 0.95)$ and $\beta_{\mathrm{Mo}} / \beta_{\mathrm{Ru}}(\sim 0.90) .{ }^{19}$ The deviation of each $\delta^{9 \mathrm{X} / 9 \mathrm{Y}} \mathrm{Mo}$ from $\beta_{\mathrm{Mo}} / \beta_{\mathrm{Sr}}=1$ was found to be only $-0.003 \%$ / amu, which is much smaller than the $\pm 0.03 \%$ / amu analytical error $( \pm 2$ $\mathrm{SD})$. Therefore, it can be concluded that the use of eqs 3 and 4 with $\beta_{\mathrm{Mo}} / \beta_{\mathrm{Sr}}=1$ is sufficient to correct for the mass discrimination of the Mo and Sr isotopes.

Application of the Analytical Technique. We applied the proposed analytical technique to NASS-5 and SAFe reference materials S1 and D2; the results are shown in Table 3, including the data for Suruga Bay deep seawater and the averages across the four samples. The ${ }^{92} \mathrm{Mo} /{ }^{98} \mathrm{Mo}$ ratio is also shown in Table 3. The resulting $\delta^{92 / 98}$ Mo exhibits the smallest relative SD because it has a large absolute value and a small analytical error due to the large relative mass difference between isotopes and their high isotopic abundances. Therefore, we suggest that $\delta^{92 / 98} \mathrm{Mo}$ is the best parameter for evaluation of the data quality. The four samples were collected from the Pacific and Atlantic Oceans, but $\delta^{9 \mathrm{X} / 95} \mathrm{Mo}$ and $\delta^{92 / 98}$ Mo were still identical. In particular, $\delta^{92 / 98}$ Mo showed a high degree of homogeneity across samples. In previous analytical methods, the ${ }^{92} \mathrm{Mo} /{ }^{98} \mathrm{Mo}$ ratio could not be obtained because $\mathrm{Zr}$ or $\mathrm{Ru}$ was used as external element. Our technique has enabled the determination of $\delta^{92 / 98}$ Mo for the first time and has demonstrated its potential.

Suruga Bay deep seawater is coastal water but has the same Mo isotopic compositions as that of the SAFe S1 and D2 samples collected from the open ocean. The salinity of NASS-5 is 30.4, which suggests this seawater was diluted with $\sim 12 \%$ river water. In the world's rivers, the average Mo concentration is $\sim 0.5 \mathrm{ppb}$ and $\delta^{97 / 95} \mathrm{Mo}$ is $0.7 \pm 0.2 \%$. ${ }^{34}$ When we use these values, NASS-5 should have a $\delta^{97 / 95}$ Mo value $0.01 \%$ lower than that of seawater. However, this difference was within the range of analytical error, suggesting that the Mo isotopic ratios are uniform in the oceans and that our data are accurate. These are the first data on Mo isotopic ratios in seawater reference materials and will be valuable for intercalibration in the future. Although the average $\delta^{98 / 95} \mathrm{Mo}$ in seawater was regarded as $2.3 \%$ in previous researches, it seems that the true value is little higher. To verify this, we will analyze the Mo isotopic compositions of seawater collected from all the world's oceans. We can analyze a large number of samples quite 
easily because several samples can be processed a day by the preconcentration method.

\section{CONCLUSIONS}

The TSK-8HQ chelating resin has excellent selectivity for Mo. We used this resin to preconcentrate Mo in seawater for precise isotopic analysis using MC-ICPMS. The preconcentration system with an optimized procedure had the following merits: (1) Mo was quantitatively recovered with no change in the isotopic composition, (2) almost all the alkali and alkaline earth metals were removed and their matrix effects were vanishingly low, and (3) the isobaric interference from the coexisting elements in the analyte solution was negligible. Using this preconcentration method and Sr-external correction, we obtained accurate isotopic ratio data for all stable Mo isotopes with a precision higher than that in previous works. Molybdenum isotopic compositions were determined in four kinds of seawater samples, including seawater reference materials. The results suggest the isotopic compositions are uniform in the oceans, with $\delta^{98 / 95} \mathrm{Mo}=2.45 \pm 0.11 \%$ and $\delta^{92 /}$ ${ }_{98} \mathrm{Mo}=-4.94 \pm 0.09 \%$ ( $\left.\pm 2 \mathrm{SD}\right)$. We will analyze samples collected from all the world's oceans to confirm this conclusion.

\section{ACKNOWLEDGMENT}

The authors are grateful to Dr. Takayuki Hanai for his help in sampling the Suruga Bay deep seawater. This work was supported by the Sasakawa Scientific Research Grant from The Japan Science Society and a Grant-in-Aid for Scientific Research from the Ministry of Education, Culture, Sports, Science and Technology, Japan.

Received for review July 4, 2008. Accepted October 2, 2008.

AC801383T 